07

\title{
Анализ сыворотки крови методом рефрактометрии при проведении противоопухолевой терапии у больных множественной миеломой
}

\author{
() Л.В. Плотникова ${ }^{1}$, А.М. Поляничко ${ }^{2}$, М.О. Кобелева ${ }^{1}$, А.А. Никехин ${ }^{1}$, М.В. Успенская ${ }^{1}$, \\ А.В. Каява ${ }^{1,3,4}$, А.Д. Гарифуллин ${ }^{5}$, С.В. Волошин \\ ${ }^{1}$ Университет ИТМО, \\ 197101 Санкт-Петербург, Россия \\ ${ }^{2}$ Санкт-Петербургский государственный университет, \\ 199034 Санкт-Петербург, Россия \\ ${ }^{3}$ Centre de Recherche en Biologie cellulaire de Montpellier (CRBM), \\ UMR 5237 CNRS, Université Montpellier, France \\ ${ }^{4}$ Institut de Biologie Computationnelle (IBC), \\ 34095 Montpellier, France \\ ${ }^{5}$ Российский научно-исследовательский институт гематологии и трансфузиологии, \\ 191024 Санкт-Петербург, Россия \\ e-mail: ljusja@mail.ru
}

Поступила в редакцию 02.08.2017 г.

Проведено исследование сыворотки крови больных множественной миеломой рефрактометрическими методами до и после прохождения курса противоопухолевой терапии. Установлено, что количество белка в сыворотке крови больных множественной миеломой, определенное по величине показателя преломления сыворотки, после прохождения курса лечения имеет тенденцию к снижению. Показано, что величина показателя преломления сыворотки крови может быть использована в качестве дополнительного критерия для оценки динамики изменений свойств сыворотки крови при прохождении курса противоопухолевой терапии.

DOI: $10.21883 /$ OS.2018.01.45369.173-17

\section{Введение}

Множественная миелома (ММ) - заболевание кроветворной системы, которое относится к группе парапротеинемических гемобластозов и характеризуется наличием моноклонального иммуноглобулина (М-протеина, парапротеина) в сыворотке крови и/или моче. Множественная миелома составляет около $1 \%$ от всех злокачественных опухолей и чуть больше $10 \%$ среди всех гемобластозов. Заболевание остается неизлечимым, несмотря на значительные успехи в диагностике и лечении данной группы больных [1].

Так как специфическим маркером большинства иммунохимических вариантов ММ является повышение количества патологического белка в сыворотке крови [2], целью проведенного исследования было выявление различий между контрольной группой здоровых доноров и экспериментальными группами (больные до и после прохождения курса противоопухолевой терапии) по показателю преломления и содержанию белка в сыворотке крови для оценки динамики рефрактометрических показателей при проведении противоопухолевой терапии. Известно, что рефрактометрия является подходящим методом анализа различных биологических объектов и была успешно применена в предшествующих работах $[3,4]$.

\section{Материалы и методы}

Образцы сыворотки крови. Для получения образцов использовались пробирки S-Monovette (Sarstedt, Герма- ния) с активатором свертывания. Собранные образцы крови оставляли в пробирках в течение 20-30 min при комнатной температуре $\left(18-24^{\circ} \mathrm{C}\right)$, после чего центрифугировали в течение $15 \mathrm{~min}$ при скорости $3000 \mathrm{rev} / \mathrm{min}$ на центрифуге Heraeus Labofuge 200 (Thermo Scientific, США). До проведения рефрактометрического анализа образцы замораживались и хранились при температуpe $-30^{\circ} \mathrm{C}$.

Рефрактометрия. Сыворотку крови доноров и пациентов исследовали на рефрактометре Abbemat 200 (Anton Paar, Австрия). Значения показателя преломления охватывают интервал от 1.30 до 1.72. Для сыворотки крови экспериментальным путем определяли показатель преломления и объемный процент белка при длине волны $589.3 \mathrm{~nm}$ и температуре $17.5^{\circ} \mathrm{C}$. Точность измерения коэффициента преломления составила $\pm 1 \cdot 10^{-4}$.

Для измерения показателя преломления образец помещался на всю поверхность призмы из искусственного сапфира (толщина наносимой пленки образца составляла $1 \mathrm{~mm}$ ) и освещался светодиодом через интерференционный светофильтр под различными углами. На границе раздела между образцом и призмой падающий пучок света либо преломлялся образцом, либо отражался обратно на призму. Отраженный пучок регистрировался матричным детектором, информация обрабатывалась прибором в автоматическом режиме и выводилась на дисплей.

Математическая статистика. Для оценки статистической значимости различий трех выборок (выборка $A-$ 
здоровые (55 измерений), выборка $B-$ больные до лечения (14 измерений), выборка $C$ - больные после лечения (8 измерений $)$ использовали одновременно $t$-критерий Стьюдента (t-test) в модификации Уэлча, применимый для выборок из нормально распределенных генеральных совокупностей с разными дисперсиями и в связи с небольшим объемом выборок дополнительно использовали $U$-критерий Манна-Уитни для выборок из генеральных совокупностей, распределение которых отлично от нормального.

В связи с высокой корреляцией показателя преломления и количества белка (>0.95 для всех выборок) использовали одномерные массивы значений показателя преломления как переменной с предположительно наименьшим шумом измерений.

Кроме того, для большей строгости теста в случае сравнения выборки $A$ с выборками $B$ и $C$ использовали односторонний критерий.

\section{Обсуждение результатов}

В работе исследовали образцы сыворотки крови больных ММ, а также здоровых доноров. Рефрактометрический метод анализа (рефрактометрия) основан на зависимости величины показателя преломления света от состава среды. При необходимости количественной оценки состава многокомпонентных смесей рефрактометрический анализ обладает рядом преимуществ, среди которых следует отметить относительную простоту в использовании, минимальное время и высокую точность анализа. К настоящему времени рефрактометрические подходы успешно используются для исследования биологических жидкостей, таких как сыворотка крови, плазма крови, моча [5].

На показатель преломления сыворотки крови в первую очередь оказывает влияние уровень протеинемии [6]. Для выявления изменений рефрактометрических показателей после проведения противомиеломной терапии измеряли показатель преломления каждого образца сыворотки крови, а также объемный процент белка. Результаты измерений показателя преломления и объемного процента белка в сыворотке крови больных ММ до прохождения курса терапии и здоровых доноров представлены на рис. 1. Зависимость показателя преломления от содержания белка в образцах сыворотки крови как больных ММ, так и здоровых доноров носит линейный характер. Отметим, что для образцов, полученных из сыворотки больных МM, характерны более высокие показатели по вышеперечисленным параметрам. t-test Стьюдента показывает достоверно значимое различие между выборками: одностороний $t$-test $A>B=2.19 \cdot 10^{-4}$. Рассчитанные значения $p$-уровня значимости ( $p$-value) меньше уровня $5 \cdot 10^{-2}$, что позволяет сделать вывод о наличии значимой разницы в показателе преломления между выборками.

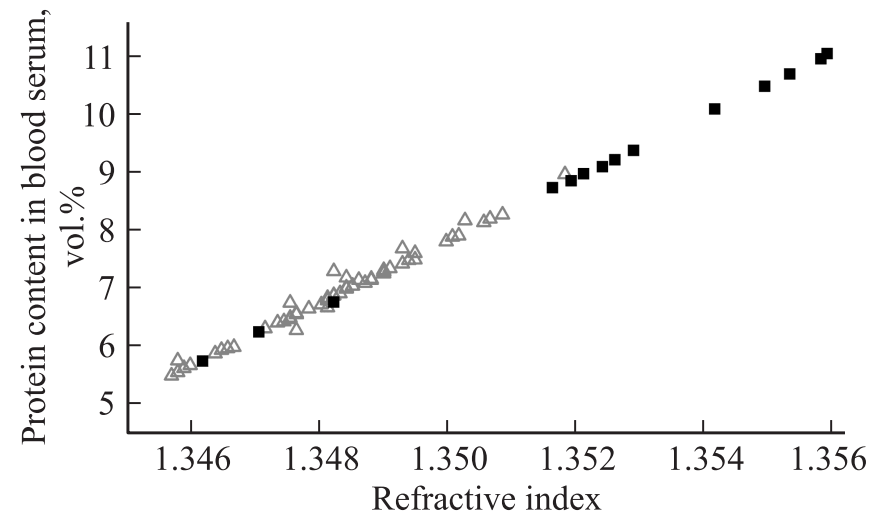

Рис. 1. Зависимость показателей преломления от количества белка в сыворотке крови здоровых доноров (треугольники) и больных множественной миеломой (квадраты) до прохождения курса противоопухолевой терапии.

Ввиду небольшого количества измерений и отсутствия однозначного подтверждения нормальности распределений в качестве контрольного критерия был применен $U$-критерий Манна-Уитни (Mann-WhitneyWilcoxon test), давший следующие результаты: одностороний $u$-test $A>B=5.9 \cdot 10^{-5}$ ( $p$-value меньше уровня $5 \cdot 10^{-2}$ ), что повторяет вывод о достоверно значимой разнице между больными множественной миеломой и здоровыми донорами по показателям преломления сыворотки крови.

В качестве основного препарата противоопухолевой терапии использовался бортезомиб. Бортезомиб является противоопухолевым препаратом, ингибирующим активность протеасомы 26S. Протеасома представляет собой ферментный комплекс, присутствующий во всех клетках и расщепляющий различные типы белков. Бортезомиб также блокирует основной фактор роста миеломных клеток, снижает резистентность опухолевых клеток к цитостатическим препаратам и, увеличивая активность общей и костной щелочной фосфатазы, способствует образованию новой костной ткани [7].

После прохождения курса противоопухолевой терапии у больных ММ наблюдается тенденция к снижению содержания белка в сыворотке крови и, как следствие, показателя преломления. Одностороний $t$-test $A>C=1.37 \cdot 10^{-2}$; двухсторонний $t$-test $B \lessgtr C=3.69 \cdot 10^{-2}$. Рассчитанные значения $p$-value меньше уровня $5 \cdot 10^{-2}$, что позволяет сделать вывод о наличии значимой разницы в показателе преломления между всеми выборками. Дополнительно проведенный $u$-test дал результаты, не согласующиеся с полученными в $t$-test: $A>C=6.59 \cdot 10^{-3}$ и $B \lessgtr C=6.53 \cdot 10^{-2}$. В случае $B$ и $C$ рассчитанное значение $p$-value больше уровня $5 \cdot 10^{-2}$, что не позволяет говорить о значимых различиях в выборках $B$ и $C$.

Тем не менее наличие достоверно значимых различий между здоровыми донорами и больными после прохождения курса противоопухолевой терапии позволяет 


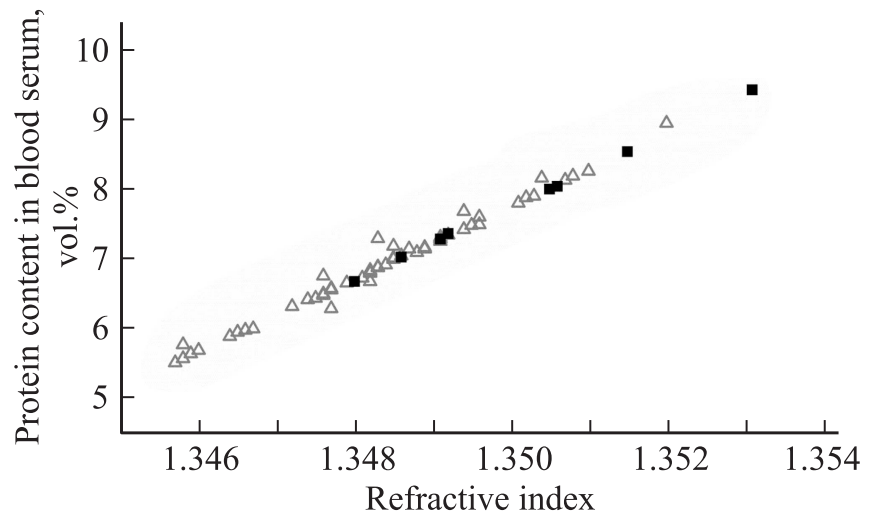

Рис. 2. Зависимость показателей преломления от количества белка в сыворотке крови здоровых доноров (треугольники) и больных множественной миеломой (квадраты) после прохождения курса противоопухолевой терапии.

говорить о том, что проведенный курс лечения позволяет понизить содержание белка в сыворотке крови больных. На рис. 2 отражена сохранившаяся линейная зависимость показателей преломления от содержания белка в сыворотке крови, но наблюдается смещение точек, соответствующих пробам больных ММ, в область графика, характерную для здоровых доноров крови.

\section{Заключение}

Проведено исследование по оценке динамики рефрактометрических показателей при проведении противоопухолевой терапии у больных множественной миеломой. Отмечено, что, как и в случае здоровых доноров, на показатель преломления сыворотки крови пациентов с множественной миеломой влияет содержание белка. После прохождения курса первичной противомиеломной терапии, основным лекарственным средством в которой являлся бортезомиб, наблюдается тенденция к снижению количества белка в сыворотке крови больных, что, в свою очередь, ведет к уменьшению показателя преломления. Таким образом, метод рефрактометрии можно рассматривать в качестве дополнительного средства оценки изменений свойств сыворотки крови при противомиеломном лечении у больных множественной миеломой.

\section{Список литературы}

[1] Multiple Myeloma. Diagnosis and Treatment / Ed. by Gertz M.A., Rajkumar S.V. NY: Springer, 2014. 311 p. doi 10.1007/978-1-4614-8520-9

[2] Handbook of Multiple Myeloma / Ed. by Mohty M., Harousseau J.-L. Adis, 2015. $90 \mathrm{p}$.

[3] Plotnikova L., Polyanichko A.M., Kobeleva M., Uspenskaya M., Garifullin A., Voloshin S. // J. Phys.: Conf. Series. 2017. V. 784. N 1. P. 012047.
[4] Плотникова Л.В., Поляничко А.М., Кобелева М.О., Успенская М.В., Гарифуллин А.Д., Волошин С.В.// Научнотехнический вестник информационных технологий, механики и оптики. 2017. Т. 17. № 2(108). С. 263-268.

[5] Стифатов Б.М., Рублинецкая Ю.В. Рефрактометрия: методические указания. Самара: Самарский государственный технический университет, 2013. 15 с.

[6] Лелевич С.В., Курстак И.А., Гриневич Т.Н., Воробьев В.В. Основы клинической биохимии. Пособие для студентов медико-диагностического факультета. Гродно: Гродненский государственный медицинский университет, 2013. $183 \mathrm{c}$.

[7] Бессмельцев С.С.// Клин. онкогематология. 2013. Т. 6. № 4. C. $379-414$. 